\title{
DEVELOPMENT AND IMPLEMENTATION OF A TRESPASS LOCATION SEVERITY ANALYSIS ON A COMMUTER RAIL RIGHT OF WAY
}

\author{
Marco daSilva \\ Systems Safety and Engineering Division \\ Volpe National Transportation Systems Center \\ 55 Broadway \\ Cambridge, Massachusetts, 02142 \\ USA
}

\section{ABSTRACT}

The United States Department of Transportation's (USDOT) Research and Innovative Technology Administration's John A. Volpe National Transportation Systems Center (Volpe Center), under the direction of the USDOT Federal Railroad Administration (FRA) Office of Research and Development (R\&D), is conducting a Trespass Prevention Research Study (TPRS) in the city of West Palm Beach, Florida. The main objective of this research is to demonstrate potential benefits, including documenting best practices and lessons learned, of implementation and evaluation of trespass prevention strategies on the rail network in West Palm Beach, Florida and all of its rights-of-way.

This paper will detail the development and implementation of a risk based data analysis to determine the locations of highest trespass risk along the TriRail commuter rail corridor through the City of West Palm Beach, FL. This feeds into the overall study objective by providing a methodology for prioritizing safety improvement programs for high-risk trespass locations.

The research team used a hazard analysis process based on the U.S. Department of Defense's MIL-STD-882 and the APTA hazard identification/resolution processes. The adaptation of this methodology facilitated the systematic identification, analysis, and resolution/mitigation of hazards for this study.

The research team also developed a risk-based prioritization algorithm for analyzing the trespass issue on the corridor. The hazard analysis and risk-based prioritization algorithm were used to identify several trespass high-risk areas along the TriRail corridor. The results of the analysis have been used by the study's stakeholder group, composed of railroads, state and local agencies, and their safety partners, to develop a set of mitigation strategies for those higher-risk locations as identified though this analysis.

\section{INTRODUCTION}

The United States Department of Transportation's (US DOT) Research and Innovative Technology Administration's John A. Volpe National Transportation Systems Center (Volpe Center) provides technical support to the US DOT Federal Railroad Administration (FRA) on all aspects of grade crossing safety and trespass research. Recently, the FRA Office of Research and Development (R\&D) funded a study on trespass prevention strategies with the ultimate goal of developing and demonstrating trespass prevention and mitigation best practices that could form the basis for national guidelines on the topic. Specifically, the Volpe Center was tasked by the FRA Office of R\&D to conduct a Trespass Prevention Research Study (TPRS) on a roughly 7-mile stretch of the South Florida Rail Corridor (SFRC) Right-of-Way (ROW), on which the South Florida Regional Transportation Authority (SFRTA) operates its TriRail commuter rail service, and 5-mile Florida East Coast Railway Company (FEC) ROW in the city of West Palm Beach, Florida, as shown in Figure 1.

The overall study used an existing initiative developed by the FRA and Transport Canada to address the trespassing issue as a starting point. The guidance document, entitled Trespassing on Railway Lines - A Community ProblemSolving Guide, details a collaborative step-by-step problem-

This material is declared a work of the U.S. Government and is not subject to copyright protection in the United States. Approved for public release; distribution is unlimited. 
solving approach for local communities [1]. The guide details the Community, Analysis, Response and Evaluation (CARE) problem-solving model. The TPRS research team used the CARE guide as a baseline for developing a plan to mitigate the trespass issue in West Palm Beach.

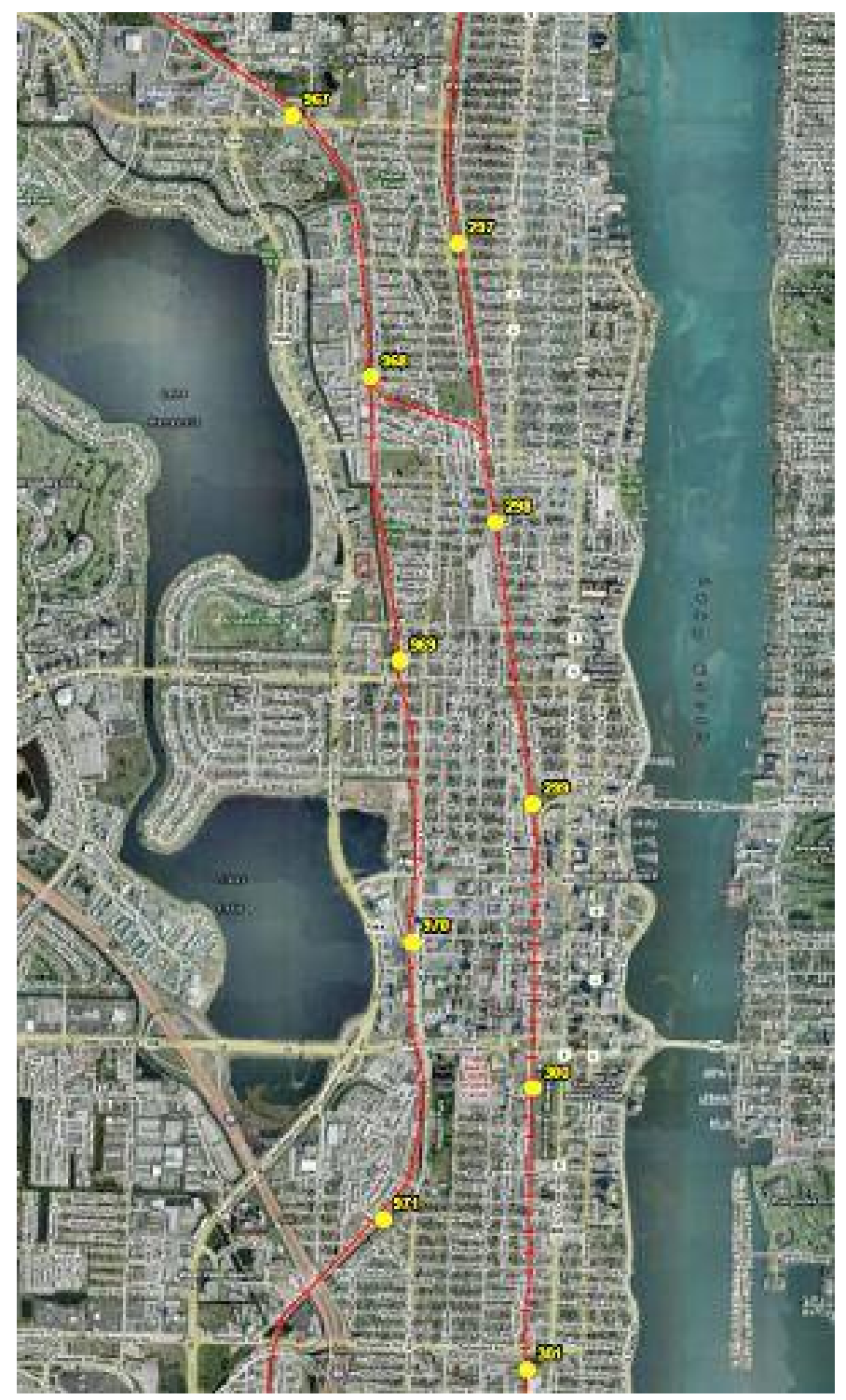

Figure 1. West Palm Beach Study Area (SFRTA Commuter Rail line on left, FEC line on right)

The CARE guidance is a collaborative problem-solving approach to addressing trespass on railroad lines in communities. This process consists of four steps:

1. COMMUNITY: Identification of the trespassing problem within the community, and the associated stakeholders
2. ANALYSIS: Data analysis of the trespassing problem and determine the underpinning causes

3. RESPONSE: Identification and implementation of the most effective response(s)

4. EVALUATION: Evaluation of the effectiveness of the treatment implemented. [1]

The problem identification, stakeholder group information, and preliminary analysis of trespass fatality and event data supplied by various entities involved in the study, and part of steps 1 and 2 of the CARE process, is contained in the Joint Rail Conference paper JRC2011-56091 entitled "Preliminary Results of the Trespass Prevention Research Study in West Palm Beach, Florida" [2].

The work detailed herein consists of a more detailed risk based data analysis of the trespass problem to determine the locations of highest risk. This feeds into the overall study objective by providing a methodology for prioritizing safety improvement programs for high-risk trespass locations. This is accomplished by:

1. Reviewing literature and develop list of practicable countermeasures for trespass mitigation

2. Developing link between collision risk and countermeasures for different types of trespass locations (ROW shortcut across, bridges/tunnels, pedestrian gate violations, etc.)

It should be noted that although the study area includes all of the rail ROW within the city of West Palm Beach, FL, the analysis presented herein focuses mostly on the SFRC. The SFRC is the corridor through which TriRail, CSX, and Amtrak operate. Risk assessment of the Florida East Coast railway corridor, the other rail ROW within the city, was not possible due to lack of trespass data.

\section{RESEARCH METHODOLOGY}

The first step in the hazard analysis process is to establish a hazard model that will be used to analyze the hazards. There are various hazard analysis techniques currently in use. A few examples are: fault tree analysis, event tree analysis, failure mode and effects analysis, and system hazard analysis.

The research team used a hazard analysis process based on the U.S. Department of Defense document "System Safety Program Plan Requirements" (MIL-STD-882) [3] and the hazard identification/resolution processes described in APTA publication "Manual for the Development of System Safety Program Plans for Commuter Railroads" [4]. As documented in the Federal Railroad Administration's document "Collision Hazard Analysis Guide: Commuter and Intercity Passenger Rail Service" [5], the FRA requests that passenger rail operators conduct this types of analysis to identify and address hazards in their systems. The process outlined in these

This material is declared a work of the U.S. Government and is not subject to copyright protection in the United States. Approved for public release; distribution is unlimited. 
documents facilitates the systematic identification, analysis, and resolution/mitigation of hazards. Additionally, it recognizes and includes any existing strategies, such as safety blitzes, currently in place. The research team adapted and applied this methodology to the trespass problem for this study.

The hazard analysis and resolution process, as described in the FRA document entitled "FRA Approach to Managing Gap Safety" [6], is composed of five steps - Define the System, Identify hazards, Assess Hazards, Resolve Hazards, and Follow-up. An alternative way of depicting this general process, specifically developed for the trespass problem is shown by the flow diagram in Figure 2, which has been adapted from a 2004 University of Waterloo proposal to Transport Canada [7]. The diagram represents a decision support model for prioritizing safety improvement programs at high risk trespass locations.

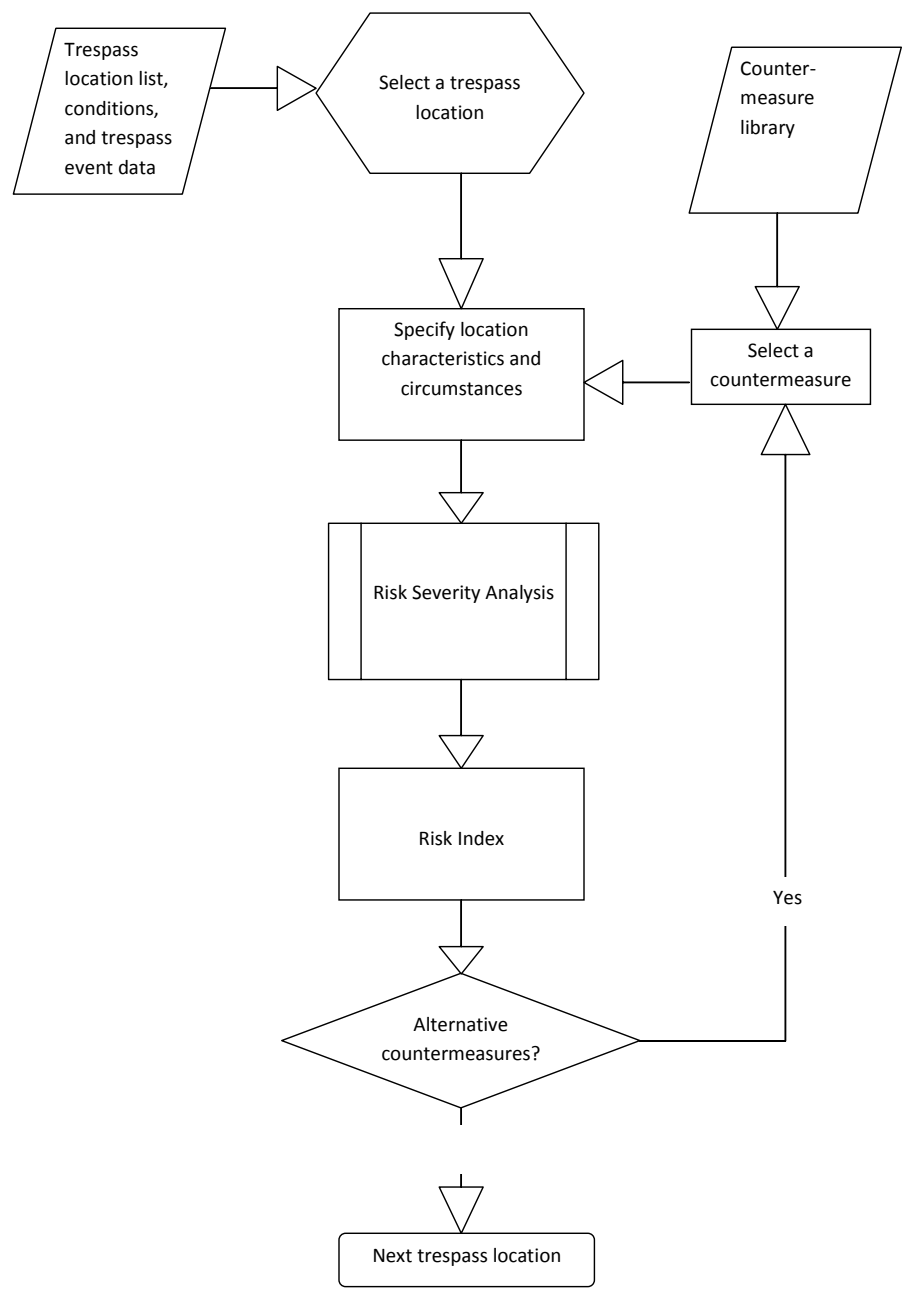

Figure 2. Countermeasure Identification and Analysis

\section{Trespass Locations}

As the model shows, the first step is to develop a list of trespass locations, after which each location's characteristics are determined. The system analyzed with this hazard analysis methodology consists of the SFRC corridor specifically bounded by Australian Avenue and Summit Boulevard within the city of West Palm Beach. The corridor was divided into 34 segments each designated with its own identification (ID) tag for the purposes of this study. In general, each grade crossing location and each section of ROW between grade crossings were designated as single segments.

The next step is to develop a set of characteristics, such as geographical attributes and other features that may contribute to trespass, associated with each location. This was achieved mainly through field observations supplemented by information supplied by stakeholders.

\section{Risk Severity Analysis}

A risk severity analysis lies at the heart of the model. Its results provide a risk severity ranking of all the locations under study after which a decision is made on whether to implement additional safety countermeasures. This paper focuses on the development and implementation of a Trespass Location Severity Analysis (TLSA), which is a risk-based prioritization scheme, used to provide a trespass risk severity estimation for the set of locations along the ROW within the 7-mile SFRC within the city.

The hazard assessment component of the analysis process is dependent on definitions of hazard frequency and severity, and a risk matrix with associated recommended levels of action. The analysis presented herein is based on the set of frequency and severity definitions as well as the risk matrix and disposition categories already established by SFRTA within its System Safety Program Plan (SSPP) [6].

\section{Frequency}

The rate of occurrence of each identified hazard needs to be estimated within the hazard analysis. One of the ways to determine/estimate the rate of occurrence is through analysis of historical data (number of incidents). However, since trespass casualties are relatively rare, surrogate measures of safety other than trespass casualties need to be considered for analysis. Examples of surrogate measures include violation data reported by local law enforcement, locomotive crew observations, and video recording of specific locations.

Specific to the TPRS, the research team identified and analyzed several sources of trespass data. These included FRA incident data, local law enforcement violation data, trespass data collected by the operating railroads (incidents, train crew observations, and analysis of locomotive video), and field observations by the research team. Although the research staff requested and received some law enforcement and locomotive crew observation data, the bulk of the analysis focused on a locomotive video data sample supplied by

This material is declared a work of the U.S. Government and is not subject to copyright protection in the United States. Approved for public release; distribution is unlimited. 
SFRTA. That data set contained video data from 613 trips dating from March 5, 2010 to July 5, 2010, and represented roughly 10 percent of all SFRTA trips through the city of West Palm Beach during that period. The analysis of this data was previously discussed in the Joint Rail Conference paper JRC2011-56091 [2]. An example of results obtained from the analysis of the locomotive video data at a specific trespass location just south of the West Palm Beach train station, identified as CP Mockingbird, is shown in Figure 3. A total of 13 out of the 116 total ROW trespass events in the overall study area were recorded at that location alone.

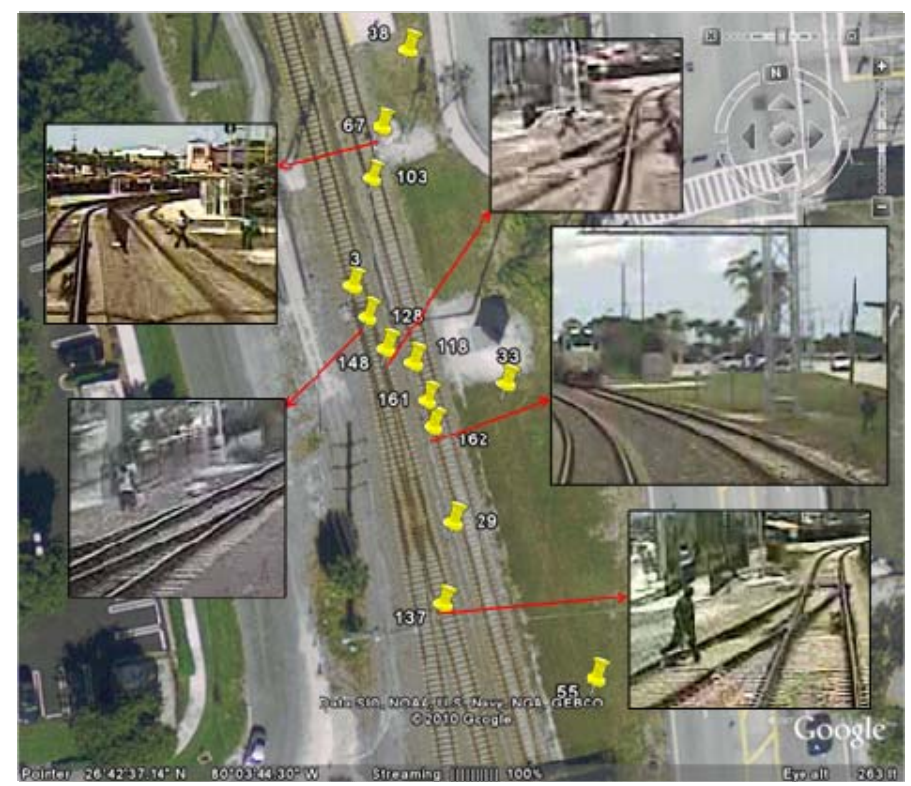

Figure 3. Trespass Data Analysis at CP Mockingbird Location

\section{Severity}

SFRTA has already developed severity definitions that it uses in its SSPP. SFRTA uses nine severity definitions, referred by SFRTA as "consequences", in their hazard management process [5]. The research team needed to revise these definitions given the focus of the study.

The research team developed an approach to classify the severity of specific trespass incidents and locations upon review of the trespass data collected by the SFRTA locomotive video. The result became a risk-based prioritization algorithm for analyzing the trespass issue on the corridor. This algorithm is based on existing strategies used by both New Jersey Transit (NJT) and Long Island Rail Road (LIRR) [8].

The prioritization algorithm is composed of a formula containing numerical values attributed to several assessment criteria. Assessment criteria examples are: prior incidents, near miss history, track curvature, sight obstructions, number of tracks, train speed, prevalent trespass type (across vs. along tracks), nearby traffic generators (schools, parks, tec.), and number of daily trains. The values are obtained by locationspecific data analysis, such as the number of fatalities and trespass events during a given period, and each criteria is assigned a weight, or point rating.

A very complex algorithm can be developed with several criteria such as breaking down the types of trespass into different severity-type categories such as loitering near or on the tracks, alcohol/drug impairment, vandalism, suicide, and others. Demographics such as age and gender could also be incorporated into the algorithm. However, there are data limitations as well as relative severity point rating issues with combining the criteria. The research team recognized this, and the need for more research to be done in the area, and therefore tailored the prioritization algorithm to the data available in the study. It should be noted that the algorithm does not differ very significantly from the LIRR formula. The major difference is the way in which the research team calculated that "trespasser report" component of the formula, which was dependent on Trespass Severity Factors (TSFs). The formula for determining the risk severity for each segment in this study was given by:

$$
\begin{aligned}
& \mathrm{PS}=\mathrm{FA}(10)+\mathrm{FS}(5)+\mathrm{DS}(2)+\mathrm{TR} \\
& \text { Where } \\
& \mathrm{PS}=\text { Priority Score } \\
& \mathrm{FA}=\text { Fatal Incidents } \\
& \mathrm{FS}=\text { Fatal Suicides (and attempts) } \\
& \mathrm{DS}=\text { Debris Strikes } \\
& \mathrm{TR}=\text { Trespass Reports }
\end{aligned}
$$

The value for Trespass Reports (TR) was given by:

$$
\mathrm{TR}=\mathrm{A} * \mathrm{TR}_{\text {crossing tracks }}+\mathrm{B} * \mathrm{TR}_{\text {along Row }}
$$

Where,

A: TSF for crossing tracks

B:TSF for walking along ROW; this could be further broken down to on tracks vs. off tracks with different TSF values

For the purpose of this analysis, the research team used the following TSF values: $A=1, B=0.5$

The majority of trespass report (TR) data in this study was obtained from analysis of the SFRTA locomotive video data, a summary of which is contained in a previous JRC paper [2]. The research team assigned different TSF values depending on the type of trespass event in an attempt to break down trespass types by severity. For example, a lower weighting value was given for a trespass event involving someone walking along the ROW, an example of which is shown in Figure 4, than for an event involving someone crossing the tracks, as shown in Figure 5. Although both of these are trespass events, the latter one involving someone crossing the tracks, and therefore the

This material is declared a work of the U.S. Government and is not subject to copyright protection in the United States. Approved for public release; distribution is unlimited. 
path of the train, is considered a higher risk event. This distinction became very useful for this study. For example, there were a large number of trespass events along a segment of ROW between $7^{\text {th }}$ Street and Banyan Boulevard of the SFRC corridor, but these events were not necessarily highrisk. Most of these involved people walking along the ROW next to Tamarind Avenue where no sidewalk exists. In contrast, 12 of the 13 events at the CP Mockingbird location previously shown in Figure 3 involved a trespasser crossing over the track, which amounts to almost 40 percent of the 31 ROW events involving trespassers crossing the tracks at nongrade crossing locations in the study area.

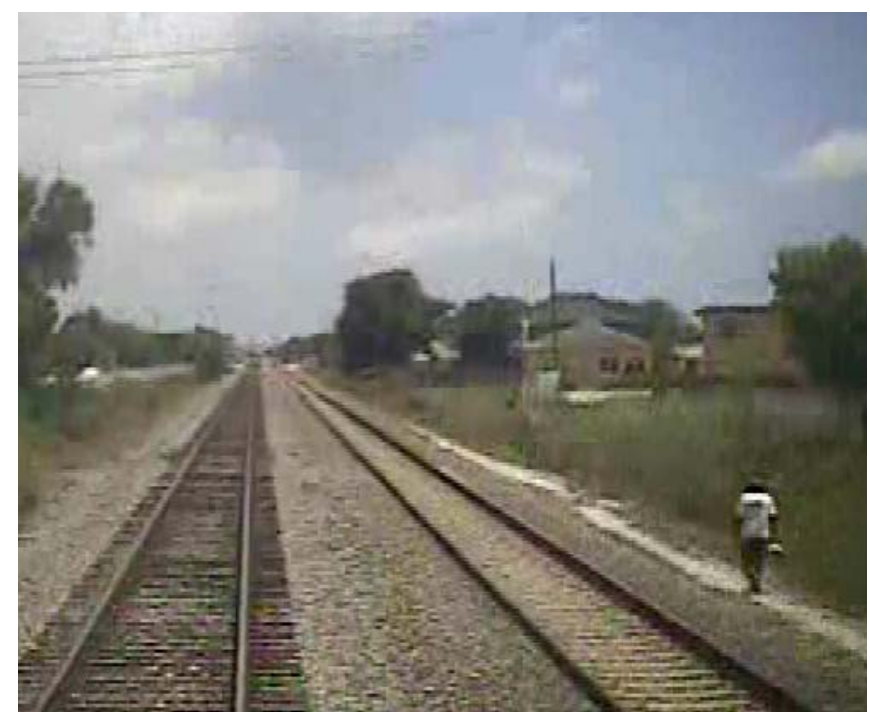

Figure 4. Trespasser Walking Along ROW on the SFRC in West Palm Beach, FL

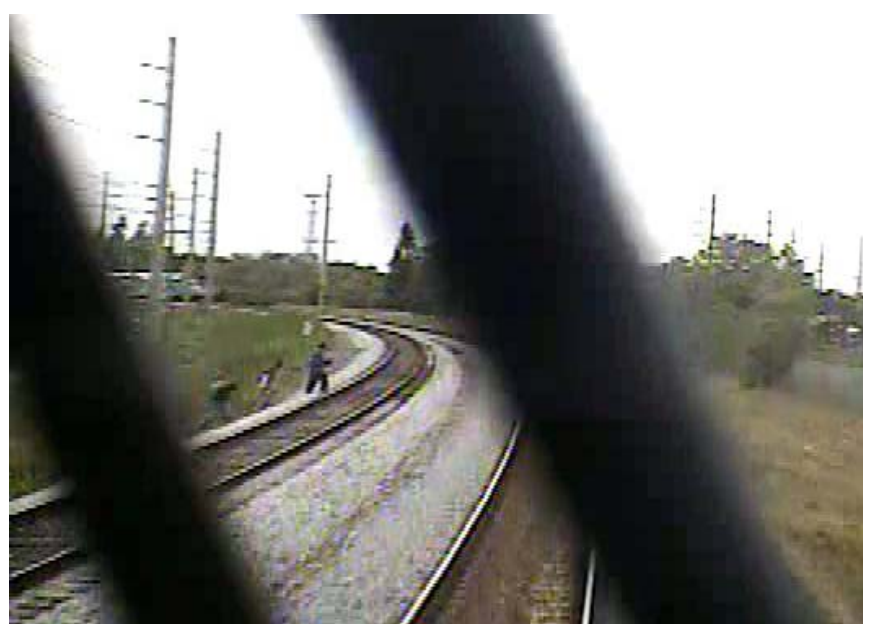

Figure 5. Trespassers Crossing Tracks on the SFRC in West Palm Beach, FL
A cross-tabulation of the frequency and severity results in what is called a risk matrix. The SFRTA risk matrix, as contained in their SSPP, is shown in Figure 6. Each group of same-color cells forms a risk category for which a corresponding disposition, or mitigation strategy, is defined within the SFRTA SSPP. For example, if the risk for a particular issue falls within the green zone then the risk may be considered acceptable, per the SFRTA SSPP definitions. On the other hand, if the risk falls within the red-colored cells, then short-term mitigation actions must be taken immediately and medium/long term mitigation plans must be developed, as defined in the SFRTA SSPP.

\begin{tabular}{|c|c|c|c|c|c|c|c|c|c|}
\hline Frequency & \multicolumn{9}{|c|}{ Consequence } \\
\hline & $\mathrm{R}$ & $\mathrm{C} 1$ & $\mathrm{C} 2$ & $\mathrm{C} 3$ & $\mathrm{C} 4$ & $\mathrm{CS}$ & $\mathrm{Cb}$ & $\mathrm{C} 7$ & $\mathrm{CS}$ \\
\hline & Satixidax & Negliglte & Mnox & \begin{tabular}{|l|} 
Manr wifh \\
Mhdeal Care
\end{tabular} & 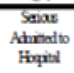 & Senas & $\begin{array}{l}\text { Serias vith } \\
\text { Mitiple } \\
\text { Iniries }\end{array}$ & Citical & Dentrour \\
\hline Catain & $\bar{R}$ & $\bar{B}$ & $\bar{B}$ & $\bar{B}$ & $\mathrm{~A}$ & $\bar{A}$ & $\bar{A}$ & $\bar{A}$ & $\bar{A}$ \\
\hline Gkely & $\overline{\mathrm{R}}$ & $\mathrm{C}$ & $\bar{B}$ & $\bar{B}$ & $\bar{B}$ & $\bar{B}$ & $\bar{A}$ & $\mathrm{~A}$ & $\mathrm{~A}$ \\
\hline Pobsible & $\mathrm{R}$ & c & $c$ & $\bar{B}$ & $\mathrm{~B}$ & $\bar{B}$ & $B$ & $\mathrm{~A}$ & $\mathrm{~A}$ \\
\hline Cnilkey & $\mathrm{R}$ & C & C & C & ( & C & B & B & $\mathrm{A}$ \\
\hline Rare & $\mathrm{R}$ & D & C & c & c & c & $c$ & B & B \\
\hline Inprodxble & $\bar{R}$ & $\bar{D}$ & D & D & D & c & C & $\bar{B}$ & B \\
\hline Incredible & $\mathrm{R}$ & $\overline{\mathrm{D}}$ & $\bar{D}$ & $\overline{\mathrm{D}}$ & $\overline{\mathrm{D}}$ & $\mathrm{D}$ & $\mathrm{D}$ & $r$ & $C$ \\
\hline
\end{tabular}

Figure 6. SFRTA Risk Matrix [6]

\section{CONCLUSIONS}

The system analyzed with this hazard analysis methodology consists of the SFRC corridor specifically bounded by Australian Avenue and Summit Boulevard, as shown in the track chart in Figure 7. As previously noted, the FEC corridor was not included in the hazard analysis due to lack of data.

The proposed Priority Score (PS) mapping to the risk classes contained in the SFRTA SSPP was defined by the research team as:
A (high risk):
PS $\geq 20$
$\mathrm{B}$ (medium risk):
$10 \leq \mathrm{PS}<20$
C (low risk):
$5 \leq \mathrm{PS}<10$
$\mathrm{D}$ (negligible risk):
$\mathrm{PS}<5$

The analysis and risk classification per the PS criteria above yielded a set of three high-risk, four medium-risk, six low-risk, and 21 negligible trespass risk segments on the corridor. The results of the TLSA, which yield a risk-based priority score for each segment of the corridor based on trespass data, are shown in the prioritized list in Table 1.

The trespass risk severity classification for each of these segments is highlighted in Figure 7. It can be clearly seen that the majority of the trespass severity risk is located along about one mile of the study area from the 7 th Street grade crossing to the CP Mockingbird location. The risk analysis resulted in medium or high-risk designations for the five segments within

This material is declared a work of the U.S. Government and is not subject to copyright protection in the United States. Approved for public release; distribution is unlimited. 
that one mile section. The risk was shown to be medium or high in only two other segments outside of that area. The segment running between 45th $\mathrm{St}$ and 36th St (A3) was deemed high-risk and the segment bounded by Carolina St and Boyd St (A27) was classified as medium-risk by the analysis. The analysis classified all other segments as either low risk or negligible risk.

Table 1. Risk-based Prioritized Segments on SFRC

\begin{tabular}{|c|c|c|}
\hline \multicolumn{2}{|c|}{ Location } & \multirow{2}{*}{$\begin{array}{l}\text { Priority } \\
\text { Score }\end{array}$} \\
\hline ID & Description & \\
\hline A16 & 7th St & 34 \\
\hline A18 & Banyan Blvd & 26 \\
\hline A3 & ROW between 45th and 36th & 24 \\
\hline A19 & ROW between Banyan Blvd and WPB Station & 17.5 \\
\hline A20 & CP Mockingbird & 12.5 \\
\hline A17 & ROW between 7th St and Banyan Blvd & 10.5 \\
\hline A27 & ROW between Carolina St and Boyd St (closed) & 10.5 \\
\hline A7 & ROW near Coleman Park & 8 \\
\hline A8 & ROW on north approach to 15th St & 6.5 \\
\hline A11 & Palm Beach lakes Blvd & 6 \\
\hline A4 & 36th St & 6 \\
\hline A22 & Okeechobee Blvd & 5 \\
\hline A5 & ROW between 36 th and 25 th & 5 \\
\hline A33 & ROW between Allendale Rd and Summit Blvd & 3.5 \\
\hline A1 & Australian Ave & 3 \\
\hline A2 & 45th St & 3 \\
\hline A21 & ROW between CP Mockingbird and Oke. Blvd & 3 \\
\hline A15 & ROW at 8th St & 2.5 \\
\hline A28 & Boyd St (closed) & 2.5 \\
\hline A24 & Old Okeechobee Rd & 2 \\
\hline A6 & 25th St & 2 \\
\hline A12 & ROW at 11th St & 1.5 \\
\hline A13 & ROW at 10 th St & 1.5 \\
\hline A10 & ROW between 15th and Palm Beach Lakes Blvd & 1 \\
\hline A14 & ROW at 9th St & 1 \\
\hline A26 & Carolina St & 1 \\
\hline A34 & Summit Blvd & 1 \\
\hline A9 & 15th St & 1 \\
\hline A23 & ROW between Oke. Blvd and Old Oke. Rd & 0.5 \\
\hline A25 & ROW between Old Oke. Rd and Carolina St & 0.5 \\
\hline A29 & ROW between Boyd St (closed) and Belvedere Rd & 0 \\
\hline A30 & Belvedere Rd & 0 \\
\hline A31 & ROW between Belvedere Rd and Allendale Rd & 0 \\
\hline A32 & Allendale Rd & 0 \\
\hline
\end{tabular}

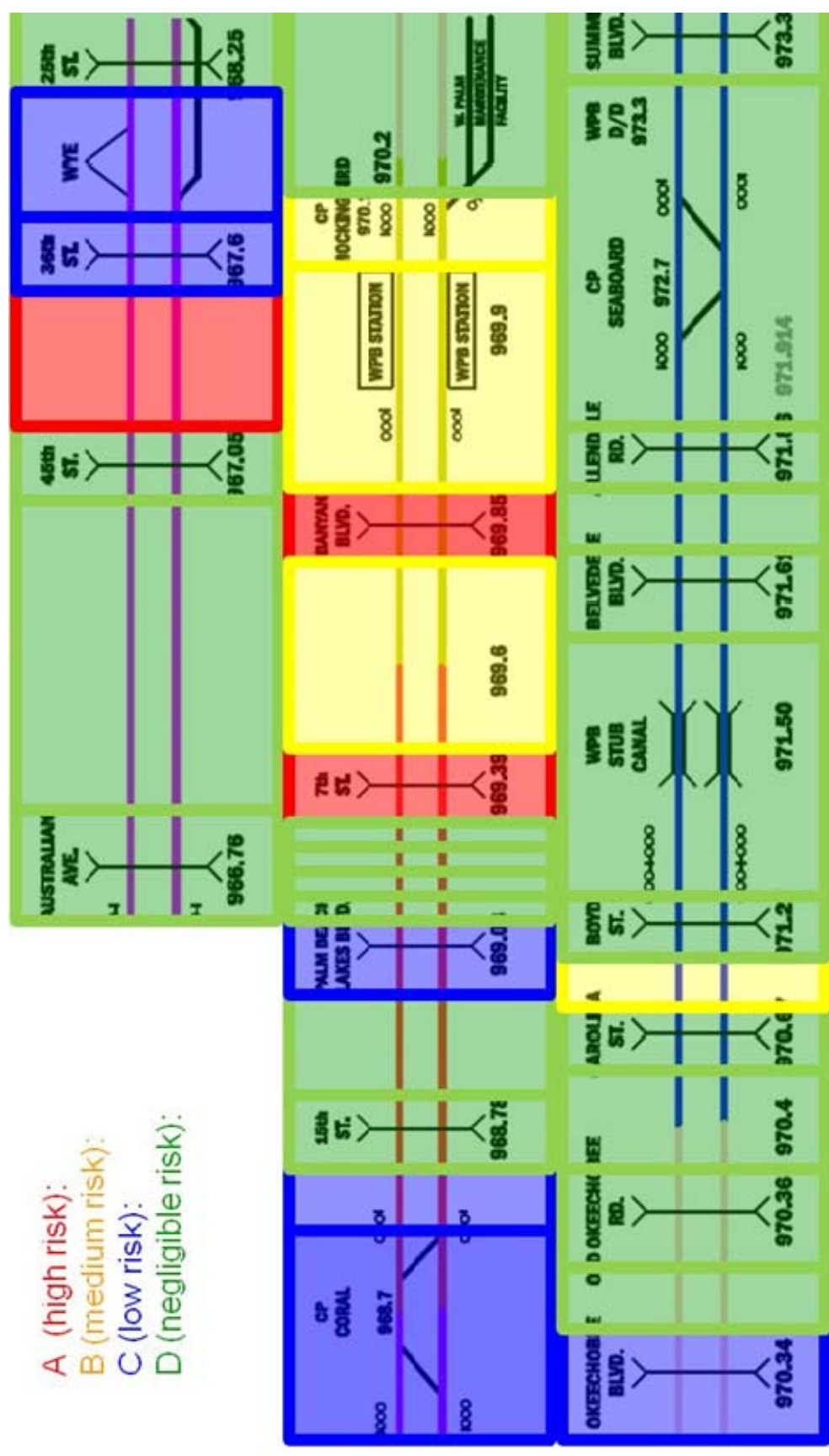

Figure 7. SFRC Corridor Map Risk Areas States. Approved for public release; distribution is unlimited. 


\section{NEXT STEPS}

As outlined in this paper, the TPRS project team has completed the first three steps in the collaborative effort to address the trespass problem in the West Palm Beach community, which involved identifying and involving all potential community stakeholders, and performing a data analysis. The research team has since moved to propose a set of feasible responses to mitigate the trespass problem, which are currently under review by the stakeholders. These responses consist of engineering (such as fences, signs, or other anti-trespass technologies, or possibly new crossings), education (such as signs, posters, public service announcements, Operation Lifesaver), and enforcement (which may also include legislative efforts). Some of these recommendations are system-wide recommendations while others are aimed to specific locations or segments of the population.

It is the hope of the research team that the stakeholders implement one or more recommendations from this study, which the research team will then evaluate. Finally, a set of national recommendations or guidelines will be developed based on the process validated through this study. These recommendations could then be used to develop model ROW trespass prevention strategies.

\section{ACKNOWLEDGEMENTS}

The author would like to thank Sam Alibrahim, Chief of the Train Control and Communications Division, FRA, and Tarek Omar, Program Manager, Train Control and Communications Division, FRA for their guidance and direction during the project. The authors would like to acknowledge Daniel Knote, Chief of the Passenger Rail Safety Division, FRA, and Michail Grizkewitsch, Highway-Rail Grade Crossing and Trespasser Division, FRA, for their technical and organizational leadership. The authors would also like to acknowledge Tashi Ngamdung of the Systems Safety and Engineering Division, Volpe Center, for his support in data collection and analysis. Additionally, special thanks to all of the members of the TPRS Stakeholders Users Group.

\section{REFERENCES}

[1] Direction 2006. Trespassing on Railway Lines, A Community Problem-Solving Guide. www.direction2006.com/documents/pdf/en_TrespGuide2 003.pdf, last accessed December 7, 2010.

[2] daSilva, M., and Carroll, A., Preliminary Results of the Trespass Prevention Research Study in West Palm Beach, Florida. Paper number JRC2011-56091. March 2011.

[3] U.S. Department of Defense. 1993. "Military Standard, System Safety Program Requirements." Mil-Std-882C. Washington, DC: U.S. Department of Defense.
[4] American Public Transportation Association. 2000. "Manual for the Development of System Safety Program Plans for Commuter Railroads." Washington, DC: American Public Transportation Association.

[5] U.S. Department of Transportation Federal Railroad Administration. 2007. "Collision Hazard Analysis Guide: Commuter and intercity Passenger Rail Service." Washington, DC: U.S. Department of Transportation. http://www.fra.dot.gov/downloads/safety/chag final 10 12 07.pdf

[6] U.S. Department of Transportation Federal Railroad Administration. 2007. "FRA Approach to Managing Gap Safety." Washington, DC: U.S. Department of Transportation. http://www.fra.dot.gov/downloads/safety/Gap_Safety_Ma nagement_Document_120707_Rev_2003.pdf

[7] University of Waterloo proposal to Transport Canada Transportation Development Centre - "A Decision Support Model for Prioritizing Safety Improvement Programs at High Risk Grade Crossings", July 2004.

[8] Adduci, B., et al, "ROW Fatality and Trespass Reduction Workshop 2008", Report No. DOT/FRA/ORS-09/001. U.S. Department of Transportation, Federal Railroad Administration, February 2009. http://www.fra.dot.gov/downloads/safety/trespass/ROWF \&TR-2008-0401-02-00.pdf, last accessed January 4, 2011.

This material is declared a work of the U.S. Government and is not subject to copyright protection in the United States. Approved for public release; distribution is unlimited. 